\title{
On the Role of the Education of Probability Theory in the Training of Applied talents of Economic Management
}

\author{
Tao Chen ${ }^{1}$ and Wenbin Liu ${ }^{1 *}$ \\ ${ }^{1}$ Deartment of Public Course, Wuhan Technology and Business University, Wuhan 430065, China
}

( ${ }^{\star}$ Corresponding Author: Wenbin Liu, email:812926096@qq.com)

Keywords: Probability theory; Applied talents of economic management; Personnel training

\begin{abstract}
Probability theory is the science of studying uncertainty, it is a course which can connect the abstract of mathematics with the problems in real economic life, and it is one of the three basic mathematics courses in higher education of our country. The object of study in many basic principles of economics and management, such as management, is the uncertainty in each discipline, so the teaching of probability theory can be related to the teaching of economics and management. The reform of curriculum based on probability theory has become the focus of many scholars. Firstly, this paper analyzes the basic concepts of probability theory and applied talents of economic management. Then, the function of probability theory teaching in the training of applied talents of economic management is analyzed.
\end{abstract}

\section{Introduction}

Probability theory is the science of studying uncertain phenomena, which seem to be inscrutable, but have certain regularity. It has become one of the three basic mathematics teaching courses in colleges and universities at present. Uncertainty appears not only in the social sciences but also in the natural sciences, so probability theory is closely related to the society, economy and life. Its application has gradually infiltrated into all fields and production departments of the society and affected the social life of contemporary people. Whether the basic knowledge of probability theory has been mastered or not has gradually become an important part of people's basic cultural literacy. The importance of learning it is recognized by more and more people. In the discipline of economics and management, probability theory is an important basic course of economics and management because most of the objects discussed in the basic principles of each discipline are related to uncertainty. It is an insurmountable basic role in the training of applied talents of economic management.

\section{The Basic Definition of Probability Theory}

Probability theory is a quantitative discipline proposed by Ian when he studies the occurrence of random phenomena. It mainly uses quantitative and qualitative methods to reveal deterministic laws in random events. The science of determining the probability of possible occurrence of random events. Like other branches of mathematics, it has extremely strict mathematical forms, but it also has its own unique "probability thinking". In the process of studying probability theory, great attention is paid to the cultivation of thinking ability, which is incomparable to any other subject. Human thinking reflects the objective world through the knowledge already mastered in the brain as a medium. It's also a process in which the brain processes and rebuilds the information it gets. It produces ideas, and it also reflects the ingenuity of the human brain. Is a core element of intelligence. The degree of mastery of probability theory is reflected in the quality of thinking, that is, in the flexibility of thinking, Profundity and agility are many aspects. Most of the questions about probability theory can be seen as an open topic, which can not only provide students with a broad thinking space and intellectual background, It can also provide students with training opportunities such as observation, collection, operation, thinking, judgment and so on. Through the study of probability theory, students can develop more comprehensive thinking ability. It can also cultivate students' correct way of thinking about uncertainty and enhance students' interest in 
mathematics learning, which is also a good subject material in the process of cultivating applied talents.

\section{The Basic Concept of Applied Talent}

Applied talents are skilled talents who apply mature technology and theory to practical production and life. Applied talents are those who are engaged in seeking direct benefits for society by using scientific principles. Its main task is to apply scientific principles or newly discovered knowledge directly to social practice, which is closely related to social production and life, and to create direct economic benefits and material wealth for society.

Compared with the training mode of other types of talents, the training mode of applied talents mainly has the following characteristics: The knowledge structure of such talents is designed around the actual needs of front-line production, with special emphasis on basic, mature and applicable knowledge in such basic work as curriculum design and textbook construction. Relative neglect of the strong pursuit of the discipline system and a high degree of concern for the frontier unknown areas. The knowledge structure of such talents is designed around the actual needs of front-line production, with special emphasis on basic, mature and applicable knowledge in such basic work as curriculum design and textbook construction. Relative neglect of the strong pursuit of the discipline system and a high degree of concern for the frontier unknown areas. The training process of applied talents emphasizes the combination of practice and practice, and pays more attention to practical teaching links, such as experiment teaching, production practice, curriculum design and so on.

In the training of applied talents of economic management, it is also necessary to broaden the channels of cultivating students' practical ability through various ways, and carry out multi-level practical teaching such as course experiment, scene simulation practice training, professional comprehensive training, practice investigation and so on. All of these processes involve the description and rule finding of uncertainty, which is studied in probability theory course.

The Effect of Probability Theory Teaching on the Cultivation of Applied Talents of Economic Management

Practical cases in probability Theory to enhance classroom interest and improve students' interest in Learning.

According to the characteristics of probability theory teaching, we should make full and reasonable use of some intuitionistic and vivid cases in the process of cultivating modern applied talents. In the process of discussion, the hot spots of the times will also be interspersed to improve the interest and realistic value of probability theory classroom. In the process of teaching, the audiovisual senses of students should be fully mobilized. To enable students to participate actively in the process of analysis and discussion, thus stimulating their interest in learning and developing their thinking ability. Arousing students' desire for knowledge. For example, in probability teaching, we can solve probability problems in different fields by means of probability knowledge. In the process of cultivating modern applied talents, we can also use some typical cases to dissect them through probabilistic knowledge. Exercise students' ability to solve many similar problems. In the process, students' thinking ability is diffused and their self-confidence in learning is increased. Increased interest in learning. For example, getting used to a probabilistic model to solve multiple practical problems in probability teaching, on the one hand, fosters students' flexibility in thinking. At the same time, this is especially important in the process of cultivating modern application-oriented talents, because it can indirectly trigger students' innovative ability in practical work.

Probability theory can improve students' ability to think about uncertainty and strengthen practical accumulation.

The most obvious difference between the course of probability teaching and other subjects is the difference in the object of study, because the subjects studied in most subjects are basically certain. The study of probability theory is mainly about the phenomenon of uncertainty and the study of random phenomena. Therefore, the study of probability theory has very high requirements for the students' broad thinking. Therefore, the teaching of probability theory also has extensive reference 
significance for other subjects. There are also great enlightenments to the cultivation of modern applied talents: that is, the cultivation of talents should constantly broaden the width of students' thinking and open up the basic thinking for students. Only in this way can we continuously innovate in the course of practice. We can also create a series of new viewpoints on the basis of learning theories. At the same time, probability theory involves a lot of difficult theoretical knowledge, such as probability distribution function, probability density, etc. Therefore, the students' understanding ability is also required. Therefore, in the process of formal explanation of probability theory knowledge, it is often necessary to add a lot of relevant cases of actual life to improve the students' ability of integration. Improve students' understanding of knowledge points.

The Teaching of probability Theory can strengthen the Innovation of Education and Teaching with students as the main body

With the continuous reform of education and teaching mode in our country, the status of students in the teaching process has changed greatly. In the process of probability theory teaching, teachers often attach importance to the cultivation of students' ability to "draw one lesson from the other three". The subjective ability of students has been brought into full play in the whole teaching process, which has a great influence on the cultivation of modern applied talents, which can cultivate the students' innovative ability, innovative thinking and innovative consciousness in the teaching process.

In order to attract students' interest, we should overcome some old concepts of subjects to design teaching. For example, we can organize comprehensive self-inquiry learning with an open problem as the center. Experience learning to enable students to use multi-disciplinary knowledge to participate in dealing with problems encountered in real life.

At the same time, it is also reflected in the innovation of teaching methods and methods. In the process of cultivating modern applied talents, we should change the traditional teaching mode with the system knowledge teaching as the core, instead of advocating and popularizing participatory and heuristic methods. The interactive mode of teaching, such as discussion mode, is very similar to the method of paying attention to students' own thinking ability in probability theory teaching. In this process, teachers are required to be able to fully arouse students' enthusiasm and initiative. Exploring the students' innovative ability. And the traditional teaching methods of mathematics are basically based on blackboard writing. In the teaching of probability theory for the cultivation of application-oriented talents, it is necessary to be good at using modern computers to introduce some new contents. New educational means such as digital audio and video and multimedia are used to realize the case teaching method in probability theory teaching, so that students can be guided into the situation of practical problems, thus arousing students' enthusiasm and initiative. In the teaching of probability theory, in order to realize the cultivation of modern applied talents, the innovation of teaching methods can also be realized.

\section{Conclusions}

Compared with other subjects of mathematical probability theory, has its own particularity, in the process of administration talents teaching reform using probability theory as a starting point for the realization of teaching reform has natural advantages. Therefore, in cultivating contemporary modern applied talents, to understand the use of probability theory to enrich the teaching view teaching methods, improve teaching effect.

\section{Acknowledgments}

This research was supported by special subject of educational informatization of Higher Education Society in China (Grant No. 2016XXYB22). 


\section{References}

[1] Henry. Stark,John W.Woods: Probability,Statistics, and Random Process for Engineers , Prentice Hall, USA, 2011,pp.44-50.

[2] Richard H. Williams: Probability,Statistics, and Random Process for Engineers, Cengage Learning, USA, 2002, pp.13-15.

[3] Acevedo Nistal, A., Van Dooren, W., Clarebout, G., Elen, J. \& Verschaffel, L.. Conceptualising, investigating, and stimulating representational flexibility in mathematical problem solving and learning: A critical review. ZDM Mathematics Education, 41(5)(2009) ,627-636.

[4] Ainsworth, S. DeFT: A conceptual framework for considering learning with MR. Learning and Instruction, 16(3) (2006), 183-198.

[5] Hogg Robert V, Craig Allen; McKean Joseph W: Introduction to Mathematical Statistics (6th ed.), Upper Saddle River Pearson, 2004, pp.95-99.

[6] Acevedo Nistal, A., Van Dooren, W., Clarebout, G., Elen, J. \& Verschaffel, L.. Conceptualising, investigating, and stimulating representational flexibility in mathematical problem solving and learning: A critical review. ZDM Mathematics Education, 41(5)(2009),627-636.

[7] J.D'Eon Marcel, Overgaard Valerie, Harding Sheila Rutledge. Teaching as a Social Practice: Implications for Faculty Development. J.Advances in Health Sciences Education, 2002, 5(2).

[8] J. Dos Santos M L, The care of patients with hematologic problems --a teaching-learning experience. J. Revista Brasileira de Enfermagem, 2002, 53(4).

[9] J. Jarvis L. Clinical teaching by community nurses in the Australian context. J. British Journal of Community Nursing, 2002, 5(12). 